\title{
The accuracy of pelvic magnetic resonance imaging in the diagnosis of ovarian malignancy in Iraqi patients in comparison with histopathology
}

DOI: https://doi.org/10.32007/med.1936/jfacmedbagdad.v60i4.5

\author{
Saba Q Issa* \\ Khaleel I. Mohson** \\ Nawras K. Fadhil $* * *$ \\ (c) 108
}

This work is licensed under a Creative Commons Attribution-NonCommercial 4.0 International License

\author{
MBCHB, DMRD \\ MBCHB, DMRD, CABMS (Radiology) \\ BSc (pharmacology)
}

J Fac Med Baghdad 2018; Vol.60, No.4 Received: Dec., 2018 Accepted: April, 2019 Published: May, 2019

\section{Abstract:}

Background: Ovarian malignancy is considered to score the highest fatality among women due to lack of significant symptoms. Early diagnosis and treatment lead to good prognosis. Magnetic resonance imaging (MRI) plays a major role in the diagnosis by detecting the lesions and assessing their appearance and consistency.

Objective: To determine the accuracy of MRI in the diagnosis of ovarian malignancy and comparing this to histopathology as a gold standard test.

Patients and methods: A follow up study was conducted in the MRI unit of the Radiology Department in Baghdad Teaching Hospital / Baghdad Medical City Complex during the period from $1^{\text {st }}$ of February to $31^{\text {st }}$ of December, 2017 on a group of thirty women with clinically suspected adnexal mass(es). All patients were examined with MRI including the diffusion-weighted imaging. Surgical specimens were taken for histopathology assessment.

Results: A total of 30 women with adnexal mass were included in this study, with a mean age of $46.8 \pm 14.9$ years. The MRI T1W image of the cystic part was dark in $(60 \%)$, while the T2W image of the cystic part was bright (80\%), T2W of the solid part was bright in $(53.3 \%)$, T2W fat saturation of the solid part was bright in the majority $(73.3 \%)$. T1W fat suppression contrast-enhanced of the solid part was avid in $66.7 \%$ of women with an adnexal mass; DWI of the solid part was bright in $(76.7 \%)$. The mean apparent diffusion coefficient (ADC) value by MRI for women with adnexal mass was $0.9 \pm 0.3 \times 103 \mathrm{~mm} 2 / \mathrm{sec}$. Histopathology mainly revealed mucinous cystadenocarcinoma in $(10 \%)$ and low-grade serous adenocarcinoma in (10\%).Validity of the results of MRI regarding malignant adnexal mass were sensitivity $(90.9 \%)$, specificity $(75 \%)$, +ve predictive value $(90.9 \%)$, -ve predictive value $(75 \%)$ and accuracy $(86.6 \%)$. The appropriate cutoff value for apparent diffusion coefficient in differentiation between malignant and benign adnexal mass was 0.97 with $100 \%$ sensitivity and $90.9 \%$ specificity.

Conclusions: MRI and diffusion-weighted imaging is a valid and reliable technique in the diagnosis and characterization of ovarian malignancy.

Keywords: Ovarian cancer, adnexal lesion, Magnetic Resonance Imaging, diffusion-weighted imaging, Histopathology.

\section{Introduction:}

MRI has brought a great jump in the detection and further categorization of adnexal masses into benign and malignant, with additional help achieved by the introduction of diffusion-weighted imaging (DWI) (1). The disease usually presents at a late stage at which time the 5-year relative survival rate is less than $1 / 3$ percent. About (15\%) are presented with a

* Ministry of Health, Bakooba Hospital
dr_sabaqais@yahoo.com
** Iraqi National Cancer Research Center,
University of Baghdad, Correspondence Email:
Khalelcabms@gmail.com
*** Dept. of Clinical biochemistry, College of
Pharmacy/Al-MustansyriahUniversity.
nawras_awn@yahoo.com

localized tumor (stage 1) where the 5-year survival rate is more than $90 \%$, (2) In general, the 5-year survival rate ranges between $30 \%-40 \%$ throughout the world and has slightly increased by $(2 \%-4 \%)$ since 1995 (3) .MRI can differentiate different types of tissue and fluid by their signal intensity characteristics. Signal intensities of a tumor depend on the presence, type, and extent of solid and cystic parts of the mass, (3) Findings in favor of malignancy include the detection of solid parts, the presence of papillary projections (vegetation), complex solid/cystic masses, and thick septa in a cystic lesion (4) Supportive features of malignancy are mesenteric, peritoneal or omental involvement, lymphadenopathy, and pelvic sidewall invasion. Investigation of the MRI features has shown that the distinctiveness and most in the keeping of 
malignancy are papillary projections in a cystic lesion, the presence of ascites, largest diameter greater than $6 \mathrm{~cm}$, and degeneration in a solid lesion(5) The discovery of pelvic ascites, although in favor of malignancy, can be seen in other begin tumor-like ovarian fibroma, both $\mathrm{T} 1$ - and $\mathrm{T} 2$ weighted images are standard sequences for pelvic anatomy and in lesion characterization respectively(6) A small field of view and highresolution images may be utilized to improve the detection of small structures such as papillary projections(7)Contrast medium enhanced fatsuppressed T1-weighted images intensify the lesion characterization by highlighting of nodules and septa in complex masses, contrast medium-enhanced scans also increase detection of omental and peritoneal implants $(8,9)$. DWI is a newly developed magnetic resonance functional imaging technique, which depends physically on water molecules diffusion rather than gross structural features and anatomical characteristics $(10,11)$ For that, the malignant tumors usually consist of haphazardly organized cells and the thus lacking the free movement of water molecules inside them (12).

\section{Patients \& Methods:}

This follow up study was conducted in the MRI unit of the Radiology Department in Baghdad Teaching Hospital / Baghdad Medical City Complex during the period from $1^{\text {st }}$ of February to $31^{\text {st }}$ of December, 2017. All women with suspected adnexal masses presenting to the Gynecology Consultancy Clinic and referred to MRI unit of in the same hospital were the study group. The inclusion criteria included age $\geq 18$ years with a clinical suspicion of an adnexal mass; while the exclusion criteria were having no histopathology report, patient with a nonovarian lesion (e.g. pedunculated fibroid, paratubal cyst), known cases of adnexal tumor, recurrent cases of adnexal tumors and women refusing to participate. Thirty women fulfilled the inclusion criteria for the study during the study period. After recording the relevant clinical history and information each case, the researcher examined the woman carefully, and a sonography examination was performed in the same department by the radiologist using ultrasound system (GE health care, Logic S7 Pro, and GE health care, Voluson E6) with a high-frequency linear probe. The patient then underwent the MRI examination following the protocol of the oncology hospital as follows: 1.5Tsystem (Aera -Siemens) with Gradient Strength; XJ Gradients (33 mT/m @ 125 T/m/s) XQ Gradients (45 mT/m @ $200 \mathrm{~T} / \mathrm{m} / \mathrm{s}$ ), by using an eight-channel high-resolution torso coil with array spatial sensitivity technique (ASSET) parallel acquisition. MR sequences: Localizer sequence in the three spatial planes, Axial T2-weighted HASTE sequence, Sagittal T2-weighted HASTE sequence, Oblique coronal T2-weighted FSE sequence, Oblique axial T2-weighted FSE sequence, Oblique axial T2weighted FSE sequence, Sagittal or axial oblique or coronal oblique fat-suppressed T2-weighted FSE sequence, Axial DWI SE EPI and Transverse and sagittal T1 fat suppression-weighted gradient-echo images before and after intravenous gadolinium injection. The biopsy material taken by the surgeon was sent to the Histopathology laboratory of Baghdad Teaching hospital. Follow up of the women was done by the researcher through phone calls and interviews for the 3-month duration to acquire the investigations and histopathology results. Ethical considerations: The ethical approval was obtained from Baghdad Teaching hospital authority; the researcher informed the responsible physician about any deterioration of women status, and a verbal and written informed consent was taken from patients.

\section{Statistical analysis:}

All the relevant data was entered using computerized statistical software; Statistical Package for Social Sciences (SPSS) version 20. Descriptive statistics presented as (mean \pm standard deviation) and frequencies as percentages. Multiple contingency tables conducted and appropriate statistical tests performed, Fishers exact test used for categorical variables. Independent sample t-test was used to compare between two means. ROC curve was used to measure the appropriate cutoff value of ADC. In all statistical analysis, level of significance ( $p$ value) set at $\leq 0.05$.

\section{Results:}

A total of 30 women with an adnexal mass were included in this study. The mean age was $46.8 \pm 14.9$ years; they were more or less evenly distributed among the age groups. The age distribution is shown in table 1.

Table 1: Age distribution of women with an adnexal mass.

\begin{tabular}{lll}
\hline Variable & No. & $\%$ \\
\hline Age mean \pm SD $(46.8 \pm 14.9$ years $)$ & & \\
\hline$<30$ years & 6 & 20.0 \\
\hline $30-39$ years & 5 & 16.7 \\
\hline $40-49$ years & 6 & 20.0 \\
\hline $50-59$ years & 7 & 23.3 \\
\hline$\geq 60$ years & 6 & 20.0 \\
\hline Total & 30 & 100.0 \\
\hline
\end{tabular}

The MRI T1W image of the cystic part was dark in $(60 \%)$, and bright in $33 \%$. T2W image of the cystic part was bright in (80\%) and dark in (13.3\%). T2W of the solid part was bright in $(53.3 \%)$, and low in $(10 \%)$. T2W fat saturation of the solid part was bright in the majority (73.3\%), and dark in (6.7\%). T1W fat suppression contrast-enhanced of a solid part was avid in $66.7 \%$ of women with an adnexal mass and minimal in $33.3 \%$ of them. DWI of the solid part was bright in $(76.7 \%)$ and dark in $(6.7 \%)$. The mean ADC value by MRI for women with 
adnexal mass was $0.9 \pm 0.3 \times 10^{3} \mathrm{~mm}^{2} / \mathrm{sec}$. All these findings were shown in table 2 .

Table 2: MRI findings of women with an adnexal mass

\begin{tabular}{|c|c|c|c|c|}
\hline Variable & No. & $\%$ & \multirow{2}{*}{\multicolumn{2}{|c|}{$\begin{array}{l}\text { No. } \\
\text { solid part }\end{array}$}} \\
\hline T1W image & \multicolumn{2}{|c|}{ cystic part } & & \\
\hline Bright & 10 & 33.4 & \multicolumn{2}{|c|}{ solid part } \\
\hline Dark & 18 & 60.0 & 4 & 13.3 \\
\hline Low & 1 & 3.3 & 23 & 76.7 \\
\hline Heterogenous & 1 & 3.3 & 3 & 10.0 \\
\hline Total & 30 & 100.0 & 30 & 100.0 \\
\hline T2Wimage & \multicolumn{2}{|c|}{ cystic part } & \multicolumn{2}{|c|}{ solid part } \\
\hline Bright & 24 & 80.0 & 16 & 53.3 \\
\hline Low & 4 & 13.3 & 3 & 10.0 \\
\hline Heterogenous & 2 & 6.7 & 11 & 36.7 \\
\hline Total & 30 & 100.0 & 30 & 100.0 \\
\hline \multicolumn{5}{|c|}{ T2Wfatsat of solid part } \\
\hline Bright & 22 & \multicolumn{3}{|l|}{73.3} \\
\hline Dark & 2 & \multicolumn{3}{|l|}{6.7} \\
\hline Low & 3 & \multicolumn{3}{|l|}{10.0} \\
\hline Heterogenous & 3 & \multicolumn{3}{|l|}{10.0} \\
\hline Total & 30 & \multicolumn{3}{|l|}{100.0} \\
\hline \multicolumn{5}{|c|}{$\mathrm{T} 1 \mathrm{~W}$ fat suppression contrast enhanced of solid part } \\
\hline Avid & 20 & \multicolumn{3}{|l|}{66.7} \\
\hline Minimal & 10 & \multicolumn{3}{|l|}{33.3} \\
\hline Total & 30 & \multicolumn{3}{|l|}{100.0} \\
\hline \multicolumn{5}{|c|}{ DWI of solid part } \\
\hline Bright & 23 & \multicolumn{3}{|l|}{76.7} \\
\hline Dark & 2 & \multicolumn{3}{|l|}{6.7} \\
\hline Low & 5 & \multicolumn{3}{|l|}{16.8} \\
\hline Total & 30 & \multicolumn{3}{|l|}{100.0} \\
\hline
\end{tabular}

Histopathology mainly revealed mucinous cystadenocarcinoma (10\%) and low-grade serous adenocarcinoma (10\%). Other histopathological findings were shown in table 3 . The validity results of MRI regarding malignant adnexal mass were sensitivity $(90.9 \%), \quad$ specificity $(75 \%), \quad$ +ve predictive value $(90.9 \%)$, -ve predictive value $(75 \%)$ and accuracy $(86.7 \%)$. All these findings were shown in table 4 .

Table 4: Validity test results of MRI findings in comparison to histopathology.

\begin{tabular}{|c|c|c|c|c|}
\hline \multirow{2}{*}{\multicolumn{2}{|c|}{ Validity test }} & \multicolumn{3}{|c|}{ Histopathology } \\
\hline & & \multirow{2}{*}{$\begin{array}{l}\text { Malignant } \\
\text { No. (\%) }\end{array}$} & \multirow{2}{*}{$\begin{array}{l}\text { Benign } \\
\text { No. (\%) }\end{array}$} & \multirow{2}{*}{$\begin{array}{l}\text { Total } \\
(100.0 \%)\end{array}$} \\
\hline & & & & \\
\hline \multirow[t]{3}{*}{ MRI } & Malignant & $20(90.9)$ & $2(9.1)$ & 22 \\
\hline & Benign & $2(25.0)$ & $6(75.0)$ & 8 \\
\hline & Total & $22(73.3)$ & $8(26.7)$ & 30 \\
\hline \multicolumn{2}{|c|}{ Sensitivity } & $90.9 \%$ & & \\
\hline \multicolumn{2}{|c|}{ Specificity } & $75 \%$ & & \\
\hline \multicolumn{2}{|c|}{ +ve predictive value } & $90.9 \%$ & & \\
\hline \multirow{2}{*}{\multicolumn{2}{|c|}{$\begin{array}{l}\text {-ve predictive value } \\
\text { Accuracy }\end{array}$}} & $75 \%$ & & \\
\hline & & $86.7 \%$ & & \\
\hline \multicolumn{5}{|c|}{$\begin{array}{l}\text { The appropriate cutoff level and the corresponding } \\
\text { validity tests values (sensitivity and specificity) for } \\
\text { MRI ADC in differentiation between malignant and }\end{array}$} \\
\hline
\end{tabular}

benign adnexal mass are shown in table 5 and figure 1, cutoff ADC of 0.97 had acceptable validity results (100\% sensitivity and $90.9 \%$ specificity) prediction of malignant adnexal mass.

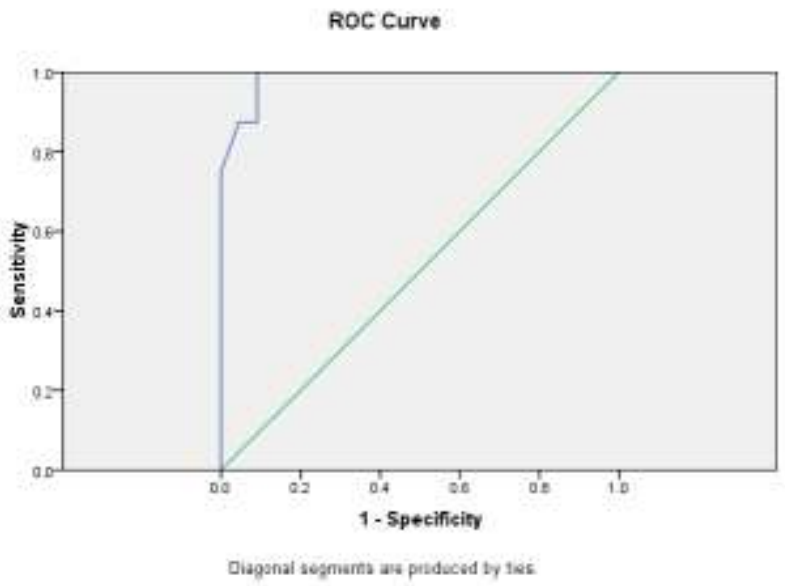

Figure 1: ROC curve for MRI-ADC value prediction of malignant adnexal mass (AUC=0.98).

\section{Discussion:}

The standard role of variable imaging modality in adnexal tumors is to reduce the occurrence of an incorrect positive diagnosis and hence avoiding surgery. This will prevent the unnecessary loss of the ovaries and / or the uterus, hence decreasing the chance of infertility. Imaging plays an important role in the early diagnosis of ovarian cancers, thus improving the surgical results and decreasing morbidity and mortality rates (13). The MRI is a leader in increasing the characterization of adnexal masses and thus increasing the specificity particularly for indeterminate lesions by ultrasound and for extremely large masses (14). The present study revealed validity results of MRI in the diagnosis of malignant adnexal tumors as sensitivity $(90.9 \%)$, specificity $(75 \%)$, +ve predictive value (90.9\%), -ve predictive value (75\%) and accuracy $(86.6 \%)$. These results regarding MRI sensitivity are close to the results of Taj-Aldean study (15) in Iraq which reported MRI sensitivity in the diagnosis of adnexal malignancy as $93.7 \%$. However, there was a difference between two studies in the level of specificity which the latter reported to be $98.4 \%$. This difference might be accredited to the larger sample size of that study compared to our study. The validity results of the current study are close to results of Fan et al (16) study in China which stated that diffusion-weighted (DW) MRI had a sensitivity of $93 \%$ and specificity of $88 \%$ in differentiating between malignant and benign adnexal masses. Our validity results of MRI are lower than results of Guerra et al (17) study in Portugal which revealed MRI sensitivity of $98 \%$, specificity of $93 \%$, +ve predictive value of $92 \%$, -ve predictive value of $98 \%$ and accuracy of $95 \%$ in the diagnosis of malignant 
adnexal masses. In Brazil, Pereira et al (18) conducted a study on 237 women with adnexal masses using ADNEX MR scoring which showed that MRI sensitivity and specificity in the diagnosis of malignancy were $94.9 \%$ and $97.5 \%$, respectively. The MRI is shown to have high sensitivity in diagnosing malignant adnexal mass approaching 96.6\% while the specificity is between $83.7 \%$ $94.0 \%(19,20)$. Anthoulakis et al (21) meta-analysis in Greece compared between MRI and other imaging tools like ultrasonography with color, spectral Doppler imaging and positron emission tomography in the examination of ultrasound indeterminate masses and shown a higher accuracy of MRI in the characterization of malignant adnexal masses reaching to a sensitivity of $90-95 \%$ and a specificity of $70-80 \%$. The current study showed that the mean ADC value by MRI for women with adnexal mass was significantly lower among women with malignancy by histopathology $(\mathrm{p}<0.001)$. This finding is consistent with results of Whittaker et al (22) study in the UK which reported that MRI-ADC values were lower in women with malignant adnexal masses than those with benign masses. Kim et al (23) study in South Korea, on the other hand, revealed no significant difference in ADC value between benign and malignant adnexal masses and reported a lower ADC values in endometrioma and teratoma as compared to malignancy, determining that ADC values were higher in tissues of cystic components than in that with solid parts. Based on that, we advise to limit the use of ADC to cases of suspected malignant lesions, not to those lesions that appear clearly benign. In Egypt, Mansour et al (24) study showed no significant difference in ADC values between malignant and benign masses of fibrous components, but pointing at a significant difference in ADC values between malignant and benign masses of fatty origin. Our study revealed that an appropriate cutoff value of ADC in differentiating between malignant and benign adnexal masses was $0.97 \times 10^{3} \mathrm{~mm}^{2} / \mathrm{sec}$, with a sensitivity of $100 \%$ and specificity of $90.9 \%$. This finding is higher than the results of Abd kadhim et al (25) study in Iraq which suggested an appropriate cutoff value of $0.92 \times 10^{3} \mathrm{~mm}^{2} / \mathrm{sec}$ for MRI-ADC with a sensitivity of $54.8 \%$ and specificity of $59.1 \%$ in differentiation between malignant and benign adnexal masses. Khaled et al (26) study in Egypt reported a cutoff value for MRI-ADC of $0.9 \times 10^{3}$ $\mathrm{mm}^{2} / \mathrm{sec}$ in differentiating between malignant and benign adnexal masses, with satisfactory validity results of $100 \%$ sensitivity and $88.9 \%$ specificity. Malek et al (27) study in Iran 47 patients with adnexal masses using 3 Tesla MRI techniques: ADC value, diffusion-weighted Imaging (DWI) and time intensity curve (TIC) of dynamic contrast-enhanced MRI in differentiating between malignant and benign adnexal masses and documented all above MRI techniques are sensitive and reliable for the diagnosis of malignant adnexal masses, but when comparing between them, they found that TIC was more valid than DW and ADC methods as the ADC is measured quantitatively to estimate the diffusion ability $(28,29)$. In the present study, women with the low T1W image of solid part and bright T2Wimage of cystic and solid parts were significantly associated with malignancy. These findings are similar to the results of Cardia study (30) in Brazil. Indeed, women in our study with bright $\mathrm{T} 2 \mathrm{~W}$ fatsat of a solid part, avid T1W fat suppression contrast-enhanced of solid part and bright DWI of the solid part were significantly associated with malignancy of adnexal mass. These findings are in agreement with results of Vargas et al (31) in USA which indicated that different MRI characteristics are significantly predictive of the malignancy of adnexal masses.

\section{Conclusions:}

The diffusion-weighted MRI is a valid and reliable technique in the diagnosis and characterization of adnexal masses. The MRI ADC value below 0.97 has a higher validity in the prediction of malignant adnexal masses.

\section{Authors' Contributions:}

Saba Qais: student ather the cases writing the research and do statistical analysis ,Khaleel Ibraheem Mohson: supervisor , give instruction about the Data collection, review he MRI sequences and review the framework of the article,

Nawras K. Fadhil, give detailed information about the contrast medium and made proof reading for the article

\section{References:}

1. Foti $P V$, Attinà $G$, Spadola $S$, et al: $M R$ imaging of ovarian masses: classification and differential diagnosis, Pictorial Review, Insights Imaging (2016) 7:21-41.

2. Reid BM, Permuth JB, Sellers TA: Epidemiology of ovarian cancer: a review Sellers Department of Cancer Epidemiology, Division of Population Sciences, Moffitt Cancer Center, Tampa 33612, FL, USA :Cancer Biol Med 2017.

3. Iraqi Ministry of Health, Iraqi Cancer Board. Iraqi Cancer Registry 2011. Iraq 2014. Available at: https://moh.gov.iq/upload/upfile/ar/273.pdf

4. Ehdaivand S. Ovary tumor, General WHO classification of ovarian neoplasm. 2014. Available at: www.pathologyoutlines.com

5. Zhang H, Zhang GF, He ZY, et al. Evaluation of primary adnexal masses by $3 T$ MRI: categorization with conventional MR imaging and diffusion-weighted imaging. J Ovarian Res 2012; $5: 33$.

6. Sohaib SA, Reznek RH. MR imaging in ovarian cancer. Cancer Image 2007(Special issue A):S119_ 129.

7. Sohaib SA, Sahdev A, Van Trappen PO, et al. Characterization of adnexal mass lesions on $M R$ imaging. AJR Am J Roentgenol 2003; 180:1297304 . 
8. Brown DL, Zou KH, Tempany CM. Primary versus secondary ovarian malignancy: imaging findings of adnexal masses in the Radiology Diagnostic Oncology Group Study. Radiology 2001; 219:213-218.

9. Thomassin-Naggara I, Balvay D, Aubert E. Quantitative dynamic contrast-enhanced $M R$ imaging analysis of complex adnexal masses: a preliminary study. EurRadiol 2011; 22:738-745.

10. Jung SE, Lee JM, Rha SE, et al. CT and MR Imaging of Ovarian Tumors with Emphasis on Differential Diagnosis. RadioGraphics 2002; 22:1305-1325.

11. Patterson DM, Padhani AR, Collins DJ: Technology insight: water diffusion MRI- a potential new biomarker of response to cancer therapy. Nat ClinPractOncol. 2008 Apr;5(4):220-33. doi: 10.1038/ncponc1073. Epub 2008 Feb 26

12. Padhani AR1, Liu G, Koh DM, Chenevert TL, et al: Diffusion-weighted magnetic resonance imaging as a cancer biomarker: consensus and recommendations.Neoplasia. 2009 Feb;11(2):10225

13. Thomassin-Naggara I, Aubert E, Rockall A, et al. Adnexal masses: development and preliminary validation of an MR imaging scoring system. Radiology 2013; 267(2):432-443.

14. Karnik A, Tembey AA, Mani S. Value of MRI in Characterizing Adnexal Masses, Photo Essay, The Journal of Obstetrics and Gynecology of India 2015; 65(4):259-266.

15. Taj-Aldean KAH. Validity of Magnetic Resonance Imaging (MRI) in characterizing adnexal masses: a prospective study. Journal of Chemical and Pharmaceutical Sciences 2017; 10 (1): 142-146. Available at: $w w w . j c h p s . c o m$

16. Fan X, Zhang H, Meng S, et al. Role of diffusion-weighted magnetic resonance imaging in differentiating malignancies from benign ovarian tumors. International Journal of Clinical and Experimental Medicine 2015; 8(11):19928-19937.

17. Guerra A, Cunha TM, Félix A. Magnetic resonance evaluation of adnexal masses. Acta Radiol 2008; 49(6):700-709.

18. Pereira PN, Sarian LO, Yoshida A. Accuracy of the ADNEX MR scoring system based on a simplified MRI protocol for the assessment of adnexal masses. Diagnostic and Interventional Radiology 2018; 24(2):63-71.

19. Heilbrun ME, Olpin J, Shaaban A. Imaging of benign adnexal masses: characteristic presentations of ultrasound, computed tomography, and magnetic resonance imaging. Clin Obstet Gynecol 2009; 52:21-39.

20. Iyer VR, Lee SI. MRI, CT, and PET/CT for ovarian cancer detection and adnexal lesion characterization. AJR Am J Roentgenol 2010; 194: 311-321.

21. Anthoulakis C, Nikoloudis N. Pelvic MRI as the "gold standard" in the subsequent evaluation of USindeterminate adnexal lesions: a systematic review. GynecolOncol 2014; 132:661-668.
22. Whittaker CS, Coady A, Culver L, et al. Diffusion-weighted MR imaging of female pelvic tumors: a pictorial review. Radiographics 2009; 29(3):759-774; discussion 774-778.

23. Kim HJ, Lee SY, Shin YR, et al. The Value of Diffusion-Weighted Imaging in the Differential Diagnosis of Ovarian Lesions: A Meta-Analysis. Cao C, ed. PLoS ONE 2016; 11(2):e0149465.

24. Mansour S, Wessam R, Raafat M. Diffusionweighted magnetic resonance imaging in the assessment of ovarian masses with suspicious features: Strengths and challenges. The Egyptian Journal of Radiology and Nuclear Medicine 2015; 46 (4): 1279-1289.

25. Abd kadhim M, Jaafer LS, Fayadh NAH, et al. Role of MRI diffusion weighted imaging in differentiation between benign and malignant ovarian masses. Al-Kindy College Medical Journal 2017; 13 (2): 28-36.

26. Ahmad KA, Abdrabou A. The significance of added $A D C$ value to conventional MR imaging in differentiation between benign and malignant ovarian neoplasms. The Egyptian Journal of Radiology and Nuclear Medicine 2014; 45 (3): 997 1002.

27. Malek M, Pourashraf M, Mousavi AS, et al. Differentiation of benign from malignant adnexal masses by functional 3 tesla MRI techniques: diffusion-weighted imaging and time-intensity curves of dynamic contrast-enhanced MRI. Asian Pac J Cancer Prev 2015; 16(8):3407-3412.

28. Thoeny HC. Diffusion-weighted MRI in head and neck radiology: applications in oncology. Cancer Imaging 2010; 10:209.

29. Ma X, Zhao X, Ouyang H. Quantified ADC histogram analysis: a new method for differentiating mass-forming focal pancreatitis from pancreatic cancer. Acta Radiol 2014; 55:785-792.

30. Cardia PP. Indications for magnetic resonance imaging of the female pelvis at a referral center for cancer. Radiologia Brasileira 2017; 50(1): V-VI.

31. Vargas HA, Barrett T, Sala E. MRI of ovarian masses. J Magn Reson Imaging 2013; 37(2):265281. 


\section{دقة الفحص بإستخدام الرنين المغناطيسي في تثخيص الاورام الخبيثة في المبيض بالمقارنة مع التشخيص النسيجي}

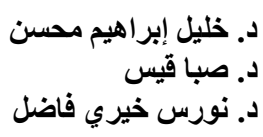

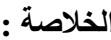

نبذة: التنخيص : المبكر و العلاج من الأورام الخبيثة للمبيض مصحوبان بتتبؤات حياتية جيدة. التصوير بالرنين الدغناطيسي له درجة عالية من الدقة

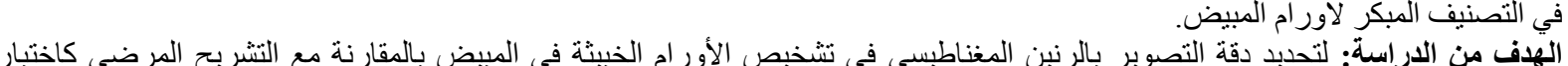
المرضى وطرق البحث: دراسة متابعة مستقبلية أجريت في وحدة التصوير بالرنين المغنطيسي في قسم الأشعة بمستشفى بغداد التعليمي في مجمع

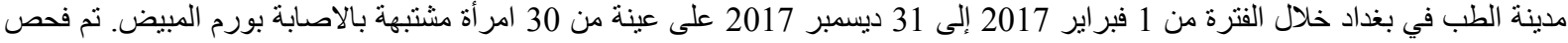

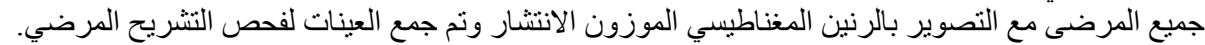

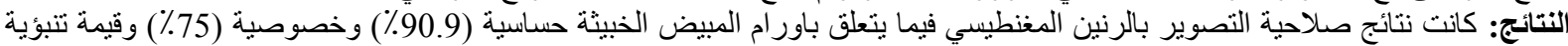
موجبة (90.9\%) وقيمة تنبؤية سالبة (75\%) ودقة (86.6\%). كانت قيمة القطع المناسبة لمعامل الانتشار الظاهر في التمايز بين الكتلة الضامة

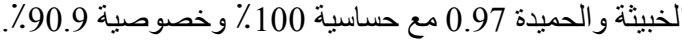
الاستتتاجات: إن التصوير بالرنين المغناطيسي الددعوم بخاصية الانتثار هو تقنتة صالحة ويمكن الاعتماد عليها في تثخيص وتوصيف اورام مفتاح الكلمات: سرطان المبيض, العقد المبيضية, الرنين المغنايسي , خاصية النفاثية للرنين المغناطيسي , الفحص النسيجي 